\title{
Analysis of spatial state of multistory building with ceiling without beams
}

\author{
Sergey Turovsky,*, and Oleg Pakhmurin ${ }^{1}$ \\ ${ }^{1}$ Tomsk State University of Architecture and Building, 634003 Tomsk, Solianaya sq., 2, Russia
}

\begin{abstract}
In this paper, we discuss a spatial work of construction structures under an influence of pulsating wind loads. There are examples of deformations those arise from incorrect arrangement of rigid structures. We consider the forms of oscillation of a frame building and show the result of their incorrect sequence. There are calculations in software and computer complex and their results are shown in the form of isofields of internal stress of enclosing structures. The results of calculations are compared with real deformations of structures. The work of a structure is considered on the example of an existing building.
\end{abstract}

\section{Introduction}

Currently, the use of fully assembled or monolithic frame buildings is intensively developing. One example of prefabricated frame construction is the system "Unified design system-2.5". It has precast concrete frame, precast-monolithic reinforced concrete floor and curtain exterior walls. Spatial rigidity and stability of the frame is provided by united joints between the prefabricated elements and using of a system of vertical links along the columns. Horizontal transmission of efforts on the columns and stiffeners is provided by the united joints of panels of the ceiling, transforming them into the hard disk in the horizontal plane. This structural system involves the construction of buildings up to 15 floors, but in the real situation there are buildings with floors exceeding the maximum number of floors provided by the system. Operating experience shows that such buildings have deformations which exceed the norms.

The object of this study is the building with the system "Unified design system-2.5" which was built in 2008. It is a seventeen-storey building, including a technical floor. The building is rectangular shape with dimensions between the modular centre axes $24.00 \times 19.90 \mathrm{~m}$. The mark of the top of the technical floor $+55.43 \mathrm{~m}$. The building has a basement. The mark basement floor is $-2.5 \mathrm{~m}$. The roof is flat.

The building was designed and built with violation of the requirements [1], because it has seventeen floors. In addition, the frame of the seventeenth (technical) floor was made in a metal version of rolled steel profiles. It should be noted that the spatial stiffness of the steel frame is significantly lower than the stiffness of the concrete frame.

It is necessary to create a significant spatial stiffness to reduce the magnitude of horizontal deformation from the wind load in residential buildings with a large number of

*Corresponding author: turovskii03@gmail.com 
floors [2]. Often pursuing the goal of the greatest economic effect, designers do not pay enough attention to ensure the spatial rigidity of the structure. This fact leads to a violation of the operational suitability of the building

Vertical rigid structures of the basement were made in the form of reinforced concrete diaphragms with a thickness of $160 \mathrm{~mm}$. On residential floors (from 1 to 16), rigid structures were made in the form of ties-struts. The concrete elements have a section of $200 \times 250 \mathrm{~mm}$.

\section{Construction solution}

According to the requirements of paragraph 5.17 [3], it is recommended to design an irregular structural system in such way that the centre of stiffness and the centre of mass of the structural system are as close as possible to the location of the resultant vertical load.

Vertical loading consists of self-weight of structures and payload, located on the ceiling and snow on the top of the building. When we analysed the design decisions of the house, we have revealed that despite of rectangular shape of the house in the plan, the design of the house has one axis of symmetry coinciding with the coordination axis "5". In the opposite direction (along the letter axes) the building is asymmetrical.

The geometric centre and the centre of mass are located between the axes "G" and "D", the stiffness elements forming the centre of stiffness in this direction located on the axis "G" (look at fig. 1).

Due to the fact that the geometric centre, the centre of mass and the centre of stiffness in the direction of the letter axes don't coincide, when the wind loads blow (static and pulsating) in the direction of the letter axes, the building "twists" around the vertical axis. In this regard, under the action of horizontal wind loads, it has significant the magnitude of the torque and corresponding deformation of the torsion, That situation is not provided in the uniform system of precast-monolithic frame [1].

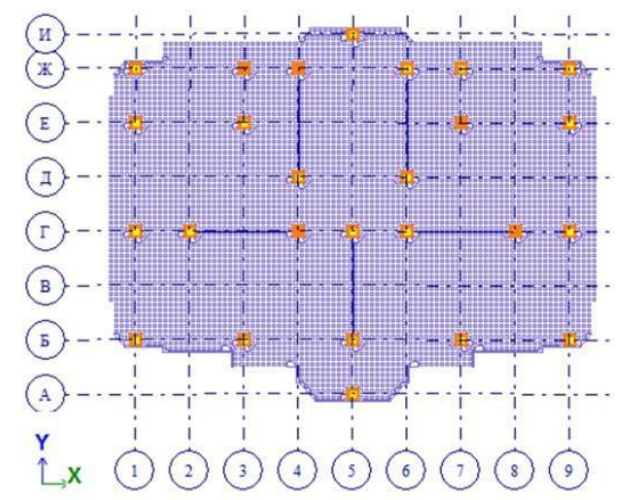

Fig. 1. Horizontal projection of the design scheme of the structure.

The calculation of the spatial system was performed on static and dynamic loads with the choice of calculated combinations of forces in accordance with SP 20.13330.2016 [4].

The calculation was made using the computer complex "LIRA-CAD" and "SCAD Office". The calculation is based on the finite element method in displacements [5]. The following loads were accepted: the own weight of the reinforced concrete frame, the weight of the roof and floors, snow load, the payload on the floors, static wind load in the direction of digital and letter axes, pulsating wind load in the direction of digital and letter axes. 


\section{Calculation result}

Due to the results of the calculation, we got and analyzed the horizontal movement of the elements of the frame of the building, the acceleration of the top floors.

In accordance with SP 20.13330.2016 [4] the first two forms of oscillation - must be flexural, and the third - torsional (look at fig. 2), or all three forms must be flexuraltorsional. The features of the structure determine the forms of self-oscillation. It does not depend on external loads and it is very important dynamic characteristic of the distribution of stiffness properties of the structure [6]. It is revealed that the first mode shape of building is torsion, second is bending-torsional, and the third is flexural. This is due to the incorrect location of the link elements in the building plan.

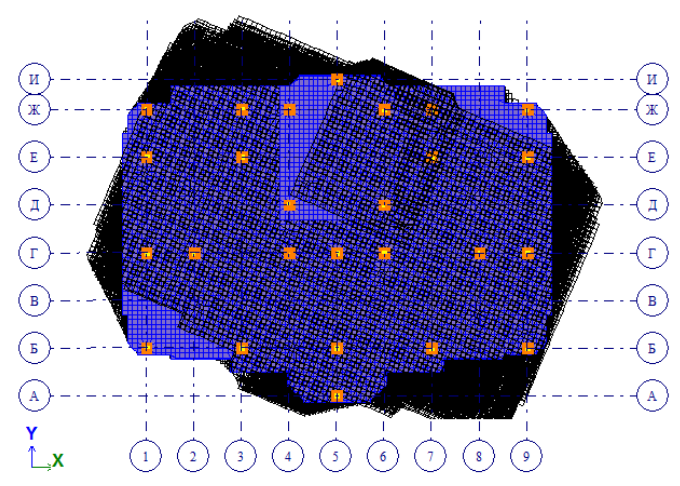

Fig. 2. The first form of vibrations of the building - torsional.

It was found that under the influence of the pulsation component of the wind load, the horizontal displacement of the frame reaches $146 \mathrm{~mm}$, and exceeds the maximum permissible, in accordance with the SP 20.1330.2016 $108 \mathrm{~mm}$ [4].

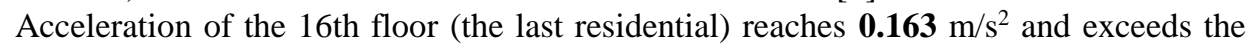
maximum permissible $\mathbf{0 . 0 8} \mathrm{m} / \mathrm{s}^{2}$, SP 20.1330.2016 [4]. This parameter is used to assess the comfort of people staying in buildings. If you exceed the maximum permissible acceleration values you don't satisfy the requirements of comfortable living.

\section{Conclusion}

The increase deformability of the building is due to insufficient rigidity of the reinforced concrete frame. The existent connections and diaphragms in the building are placed incorrectly, and as a result, in addition to excessive horizontal movements of the building, there is "twisting" around vertical axis due to the mismatch of the centre of mass and the geometric centre of the building, it exacerbates the manifestation of defects in the enclosing structures. It leads to the formation of excessive distortions of structural cells and, as a consequence, the violation of the exploitation functions of the outer walls, internal partitions of the building, the opening of seams, the formation of cracks, as a result it loses heat and pass noise on residential and non - residential apartments (look at fig. 3,4). 


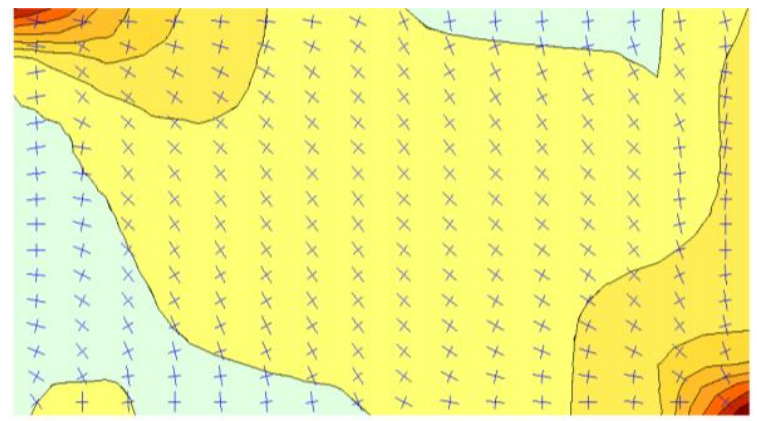

Fig. 3. Map of tensile stress in an ordinary wall. The maximum tensile stress is $38 \mathrm{kN} / \mathrm{m}^{2}$.

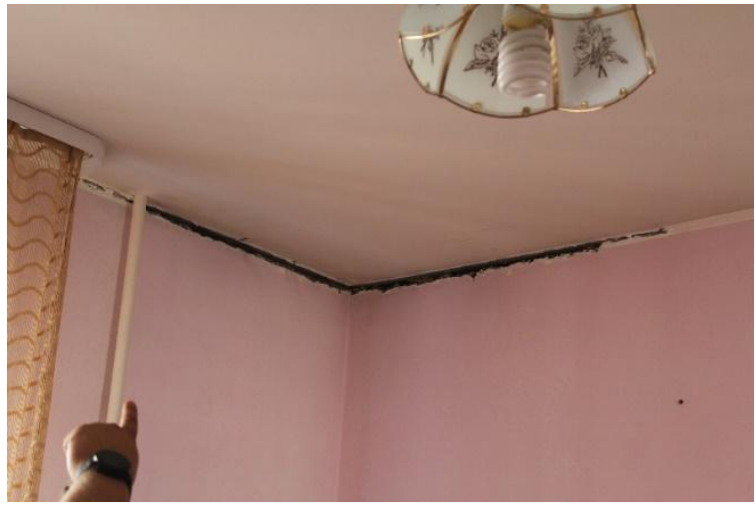

Fig. 4. Examples of cracks that formed between floor slabs and vertical wall filling.

Due to the transfer of loads from the columns to the outer walls, the enclosing structure has cracks which don't provided by the project. These effects are particularly evident in the places of stress concentration - window and door (look at fig. 5, 6).

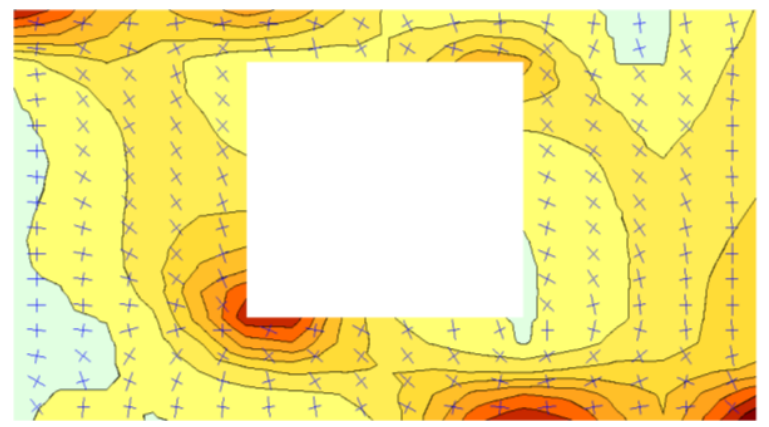

Fig. 5. Map of tensile stresses in the ordinary wall with a window. Maximum tensile stress is $13 \mathrm{kN} / \mathrm{m}^{2}$. 


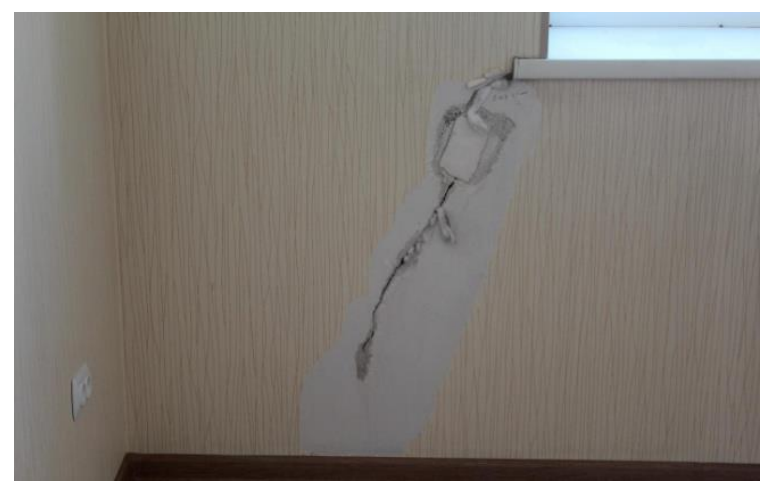

Fig. 6. Examples of cracks that formed in the stress concentration zone in the corner zones of window.

Thus, on the basis of the performed calculations, we concluded that the building has increased deformability, reduced resistance to the action of horizontal wind loads.

\section{References}

1. The unified system of precast-monolithic stickless frame "Unified design system-2.5", 491 (NPSO “Monolit”, Moscow, 1990), (in Russian)

2. V.I. Murashev, E.E. Sigalov, V.N. Baykov "Reinforced concrete structures", 592 (Moscow, 1962) (in Russian)

3. SP 52-103-2007, "Reinforced concrete monolithic structures of buildings", 22 (Moscow, 2007) (in Russian)

4. SP 20.13330.2016, "Loads and actions", 104 (Moscow, 2016) (in Russian)

5. O.G. Kumpyak, Z.R. Galyautdinov, O.R. Pachmurin, V.S. Samsonov, "Reinforced concrete and stone structures", 673 (ASV, Mocsow, 2014) (in Russian)

6. E. Simiu, R. Scanlan “Wind effects on structures”, 143 (Москва, 1984) (in Russian) 